\title{
SPANXB1 Positive
}

National Cancer Institute

\section{Source}

National Cancer Institute. SPANXB1 Positive. NCI Thesaurus. Code C142845.

An indication that SPANXB1 expression has been detected in a sample. 